\title{
Microstructure and mechanical properties of an austenite NiTi shape memory alloy treated with laser induced shock
}

\author{
Xi Wang*, Weiguang Xia, Xianqian Wu, Yanpeng Wei, Chenguang Huang \\ Key Laboratory for Mechanics in Fluid Solid Coupling Systems, Institute of Mechanics, Chinese Academy of Sciences, Beijing 100190, China
}

\section{A R T I C L E I N F O}

\section{Article history:}

Received 24 December 2012

Received in revised form

7 April 2013

Accepted 16 April 2013

Available online 23 April 2013

Keywords:

Laser shock peening

Shape memory alloy

Plastic deformation

Amorphization

Superelasticity

\begin{abstract}
A B S T R A C T
In this study, microstructure and mechanical properties of an austenite NiTi alloy treated with laser shock peening (LSP) was investigated. It was found that the thickness of shock affected layer is about $250-300 \mu \mathrm{m}$. The surface hardness of the specimen is increased by approximately $10 \%$ after LSP. Laser induced shock introduces slightly residual compressive stress in the peened specimen. The superleastic stress-strain curves of the fully LSP processed NiTi material show no change in phase transition stress, about $100 \mathrm{MPa}$ decrease in martensite yield stress, and a loss of maximum transition strain about $12 \%$ after LSP. The ultrahigh-strain-rate plastic deformation by LSP results in dislocation substructure and amorphization underneath the surface which are responsible for the hardness increase and superelastic strain loss.
\end{abstract}

(c) 2013 Elsevier B.V. All rights reserved.

\section{Introduction}

Shape memory alloys (SMAs) are one of the most popular active materials that derive their unique properties such as shape memory and superelastic effects from a thermoelastic martensitic transformation [1]. They have been increasingly used as candidate materials for medical devices and microelectromechanical systems (MEMS). The wear resistance and fatigue performance are two of major concerns in those applications [2]. For conventional engineering alloys such as stainless steels and titanium alloys, several surface treatment techniques such as shot peening have been widely used to improve those two properties in metallic components of bulk materials [3-5]. For SMAs, besides the improvement of wear and fatigue performance, the shape memory characteristics of the materials often require being preserved in their applications. Moreover, for small-scale materials and complex structural geometry used in medical devices and microsystems, processing techniques with precise control of localized treatment are needed. Recently developed laser shock peening (LSP) technique seems to have advantages over those issues [6,7]. In LSP process, a shock wave is generated and propagates into the target through the interaction of a pulsed high-intensity laser beam and absorption layer on the metallic target surface. If the amplitude of the shock wave exceeds the Hugoniot elastic limit (HEL) of the target material, plastic deformation occurs and residual compressive stresses are induced near the material surface, resulting in the

\footnotetext{
* Corresponding author. Tel/fax: +86 1082544256 .

E-mail address: xiwang@imech.ac.cn (X. Wang).
}

enhancement of fatigue life. Since the beam size could be easily adjusted, localized micro-scale peening technique has been developed and applied on the metal films in semiconductor industry $[8,9]$. In addition, LSP is suitable in processing materials with complex structural geometry by manipulating laser beam and utilizing liquid confining media like water. Therefore, LSP has great potential to treat SMAs and modify their surface properties for practical applications. Most recently, Liao et al. [10] used laser induced shock to generate residual deformation induced martensite (DIM) in a NiTi alloy. However, the thermo-mechanical properties of NiTi alloys after the LSP process and their relationships with the microstructure evolution have not been reported yet. Moreover, in a LSP process, the peak pressure of laser induced shock is at the level of several GPa, and the shock duration is in the nanosecond scale. The strain rate achieved on the target surface can be as high as $10^{5}-10^{7} / \mathrm{s}$. The existing literature on high strain rate behavior of SMAs is not extensive and has controversy. Using the Hopkinson pressure bar technique, Nemat-Nasset et al. [11] reported the existence of a critical strain rate (around $10^{4} / \mathrm{s}$ ) above which the austenite phase deforms by direct dislocation-induced plastic slip instead of transforming to martensite. The ultra-high strain rate response of SMAs needs more experimental investigation to clarify this issue.

In this study, an austenite NiTi alloy was processed by LSP with various laser power densities. The effects of laser power density on residual stress, microhardness, and superelastic stressstrain behavior were investigated. The microstructure is characterized by X-ray diffraction (XRD) and transmission electron microscopy (TEM). 


\section{Experimental procedures}

\subsection{Sample preparation}

Commercially available NiTi polycrystalline sheets were purchased from GEE Shape Memory Alloy Inc. (Beijing, China). The nominal alloy composition was Ni-50.9\% and Ti-49.1\% (at\%). The size of the grain is about $30 \mu \mathrm{m}$ as observed by optical microscopy (see Fig. 1a). As shown in Fig. 1b, the microstructure examination with transmission electron microscopy (TEM) shows the NiTi specimen consists of austenite NiTi phase with $\mathrm{Ni}_{4} \mathrm{Ti}_{3}$ precipitates. The transformation temperatures determined by differential scanning calorimeter (DSC, Perkin Elmer Diamond) were $M_{s}=285 \mathrm{~K}, M_{f}=271 \mathrm{~K}, A_{s}=277 \mathrm{~K}, A_{f}=286 \mathrm{~K}$ (see Fig. 2). Therefore the alloy is in austenite phase and exhibits superelasticity behavior under stress at room temperature. Before LSP, the sample surface was ground using a sequence of increasing grit sandpaper followed by final polishing with $0.05 \mu \mathrm{m}$ diamond paste.

\subsection{LSP processing}

The schematic of LSP experiment is shown in Fig. 3. A selfadhesive black paint ( $180 \mu \mathrm{m}$ thick) was attached to the surface of the NiTi sample used as an absorption layer and the water is used as a confining layer to constrain the plasma generated by the laser irradiation. Another NiTi sheet was attached to the back of the NiTi
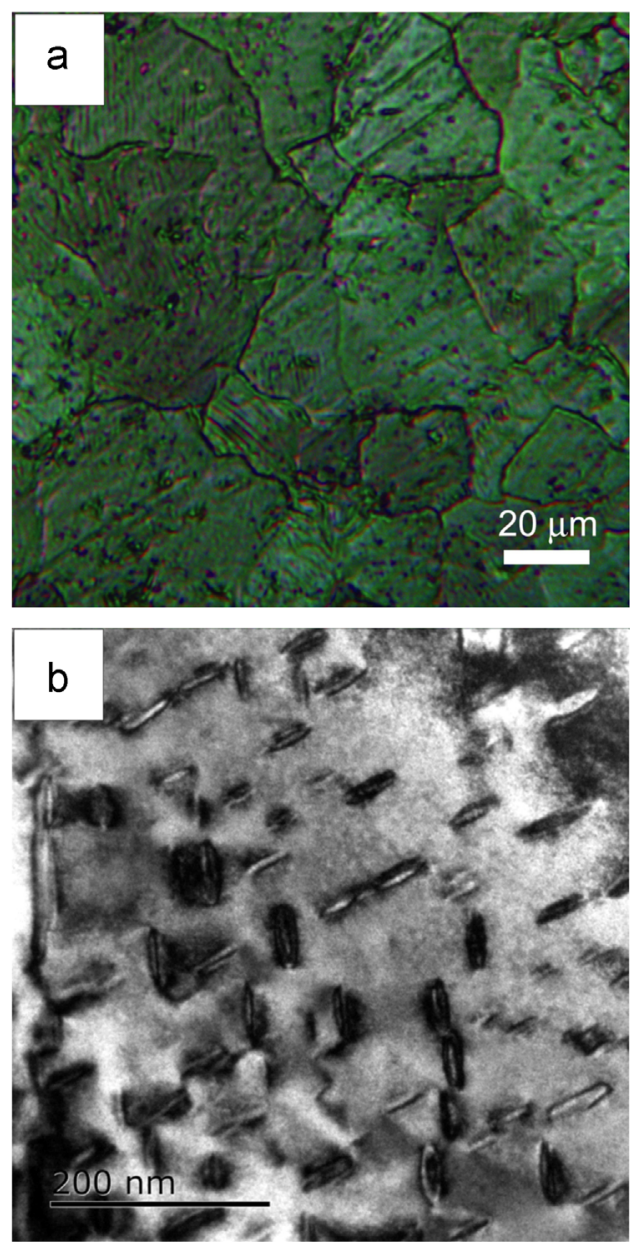

Fig. 1. Microstructure of as-received NiTi alloy. (a) Optical micrograph showing the grain size is about $30 \mu \mathrm{m}$. (b) TEM micrograph showing the NiTi matrix with $\mathrm{Ni}_{4} \mathrm{Ti}_{3}$ precipitates.

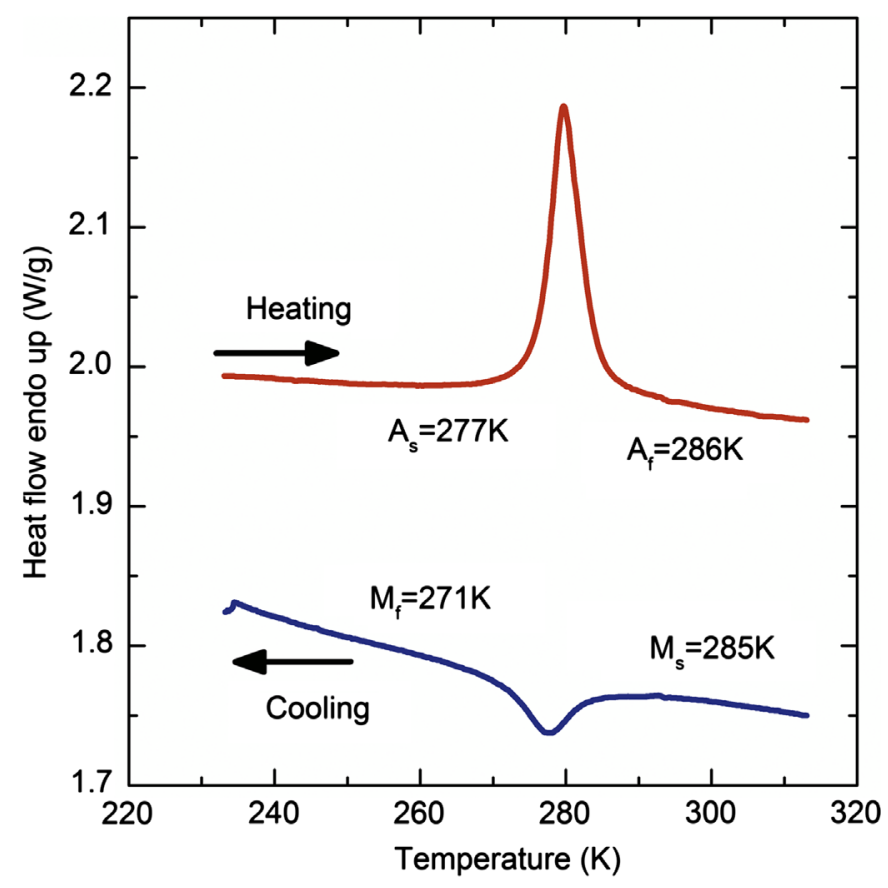

Fig. 2. Differential scanning calorimeter (DSC) curves of as-received NiTi alloy.

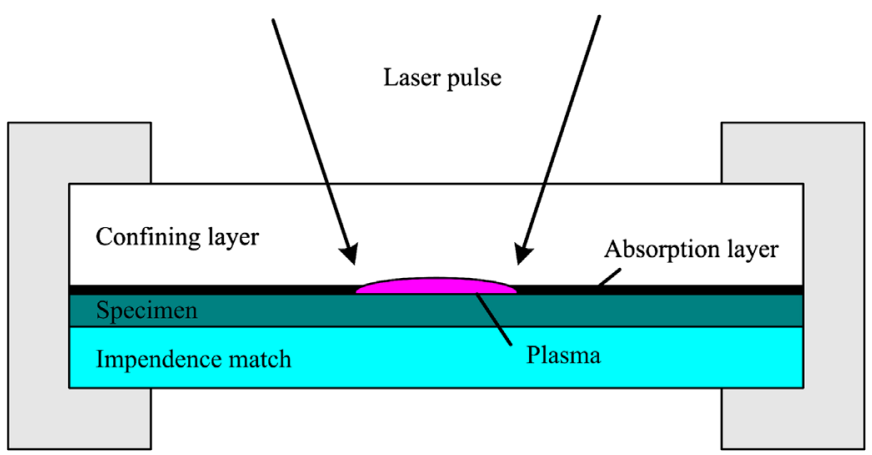

Fig. 3. The schematic of LSP experiment.

sample as a cushion layer to match the impendence. The laser pulse was delivered by a Q-switched Nd:YAG pulse laser (Spectra Physics-Quanta Ray) with a wavelength of $1064 \mathrm{~nm}$. The energy of single laser pulse is about $2.4 \mathrm{~J}$ and the pulse duration (full width at half maximum, FWHM) is approximately $10 \mathrm{~ns}$. A focusing lens was used to adjust the beam size. The diameter of the focused laser beam on the specimen varies from 2.6 to $3.0 \mathrm{~mm}$, resulting in the laser power density achieved at the sample surface varying from 3.4 to $4.4 \mathrm{GW} / \mathrm{cm}^{2}$ in this study. To create a large treated area, multiple laser shots were applied on the specimen and the overlap ratio was $50 \%$ controlled by an $\mathrm{x}-\mathrm{y}$ table.

\subsection{Property characterizations}

The Vickers hardness of the peened sample was measured by a micro-hardness tester MH-5L. A diamond Vickers indenter with a face angle of $136^{\circ}$ was used. The hardness was measured under a load of $200 \mathrm{~g}$ and a holding time of $10 \mathrm{~s}$ at room temperature. The LSP affected depth in NiTi sample was characterized with micro-hardness measurements on the cross-section of peened sample. The surface micro-hardness was also measured to evaluate the effect of surface modification. The sites for hardness tests on cross-section of peened sample are in a zig-zag fashion 
and those for hardness tests on peened surface were randomly chosen. The typical distance between the two neighboring sites is above $250 \mu \mathrm{m}$ to avoid possible interference of measurements. The diagonal lengths of an indentation were measured to obtain the Vicker micro-hardness. For surface micro-hardness, an average of six measurements was used for each data point.

Tensile testing was carried out to evaluate the superelastic behavior of NiTi alloy after LSP. Dog-bone samples with a gauge length of $4 \mathrm{~mm}$ and a gauge width of $2 \mathrm{~mm}$ were cut from a $0.4 \mathrm{~mm}$ thick NiTi alloy sheet. Both sides of the gauge area were processed by LSP. To cover the gauge area, multiple laser shots (50\% overlapping ratio) were applied along the tensile axis of the dog-bone sample. A micro-tensile tester (Gatan Microtest 2000) was used to conduct the uniaxial tensile test. The tensile test was conducted in displacement control mode with the velocity of the cross-head at $0.5 \mathrm{~mm} / \mathrm{min}$, giving the nominal strain rate at $4 \times 10^{-3} \mathrm{~s}^{-1}$. During the test, the load was measured by a $2 \mathrm{kN}$ load cell and the image of the gauge area was recorded by an CCD camera mounted on a standard optical microscope. The strain of the gauge section is extracted from those images by use of a digital image correlation (DIC) technique [12].

\subsection{Microstructure characterizations}

The sample for XRD characterization is $10 \times 10 \times 1 \mathrm{~mm}^{3}$ in dimension. Multiple laser shots were applied to cover the whole surface with $50 \%$ overlapping. Rigaku ULTIMA IV XRD system was utilized to characterize the phases before and after LSP. Rigaku D/MAX2500 XRD system was utilized to evaluate the residual stress at the sample surface using standard $\sin ^{2} \Psi$ technique. Both XRD systems use the characteristic $\mathrm{Cu}-\mathrm{K}_{\alpha 1} \mathrm{X}$-ray source. The residual stress was determined with the equation

$\sigma_{\phi}=-\frac{E}{2(1+\nu)} \cos \theta_{o} \frac{\partial 2 \theta_{\phi \psi}}{\partial \sin ^{2} \Psi}$

where the material constants $E=35 \mathrm{GPa}$ and $\nu=0.33$ for austenite NiTi alloy are used. Residual stress measurements were made with the diffraction from the (211) crystallographic planes of the austenite phase of $\mathrm{NiTi}$ (B2 phase) with the peak position $2 \theta_{\mathrm{o}}=77.57^{\circ}$.

The TEM samples were prepared from the top surface of the peened sample by the focused ion beam (FIB) lift-out method in an FEI DualBeam 820 system. TEM was performed with a JOEL-2010 operated at $200 \mathrm{kV}$.

\section{Results and discussion}

In Fig. 4, Vickers indentation tests on the cross-section of peened sample shows that the measured hardness increases in the surface layer, and then decreases to the value of untreated specimens at a depth about $250-300 \mu \mathrm{m}$, which indicates that the thickness of the LSP affected layer is about $250-300 \mu \mathrm{m}$ for the laser parameters in our study. The surface hardness of untreated specimen is $277 \pm 5 \mathrm{~kg} \mathrm{~mm}^{-2}$. The surface hardness of peened specimen are $304 \pm 9,304 \pm 9$ and $303 \pm 7 \mathrm{~kg} \mathrm{~mm}^{-2}$ for laser power density $3.4,3.8$ and $4.4 \mathrm{GW} / \mathrm{cm}^{2}$ respectively. As the indentation depth is only about $10 \mu \mathrm{m}$, the hardness values obtained on the top surface of peened sample are representative of the LSP affected layer alone. The increase in surface hardness shows no dependence on the laser power density in the range of this study. Because the sites for hardness tests on peened surface were randomly chosen and the Vickers indent diameter is about $30 \mu \mathrm{m}$ which is about the same to the mean grain size, it is very likely some of the measurements are near the grain boundary. However, we do not see obvious fluctuations in measured

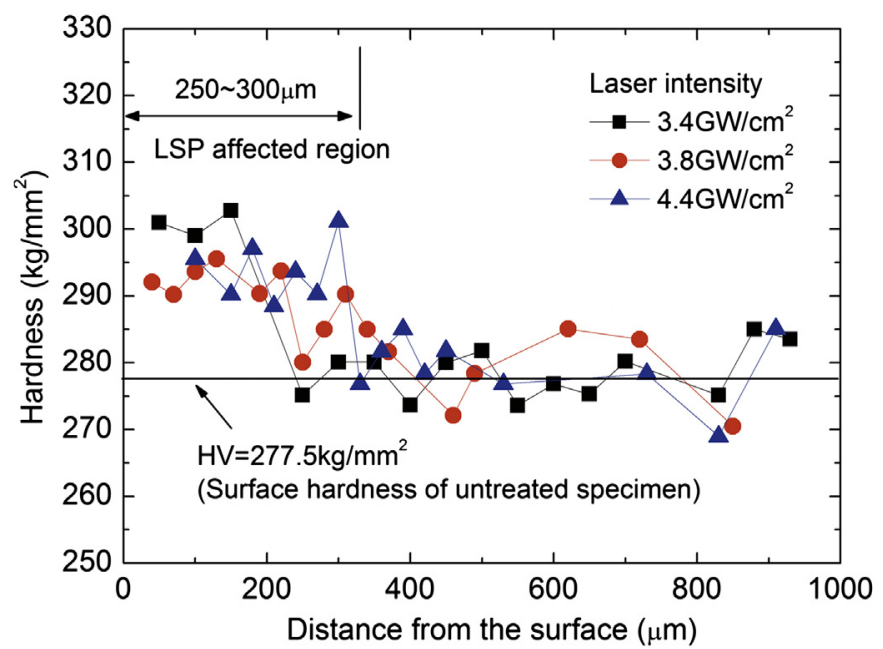

Fig. 4. Vickers hardness as a function of the depth on the cross-section of peened sample.

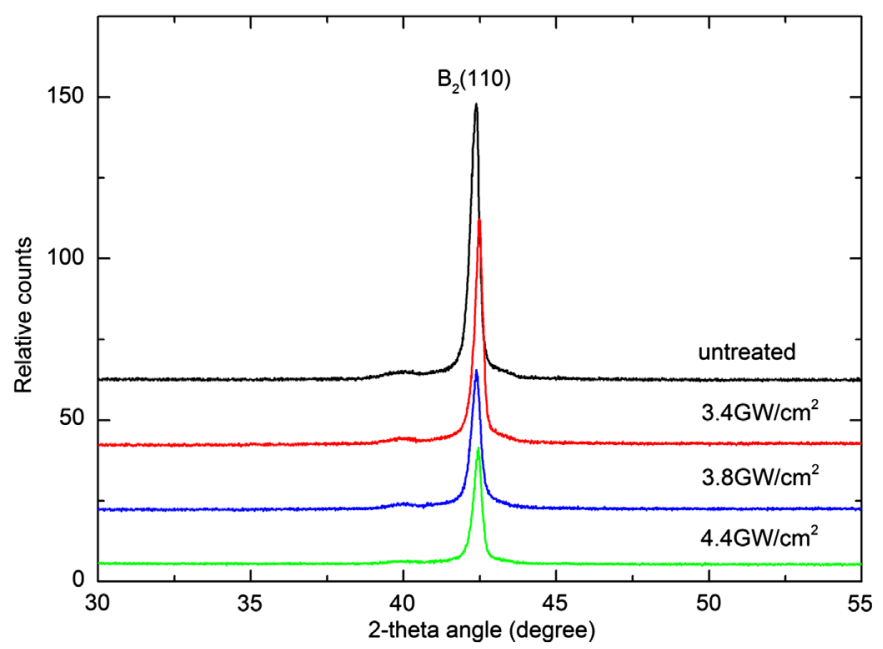

Fig. 5. XRD spectra of NiTi subjected to LSP with various laser power densities.

hardness values, indicated by small standard deviation. This indicates that the effect of indentation on grain boundary has little influence on the apparent hardness values. It is because the measured hardness is contributed by the response of a volume of material underneath the indenter, which could consist of hundreds of grains. Grain boundary has significant influence on measured hardness values if nanoindentation tests were conducted. Moreover, the specimen surface is peened with the $50 \%$ overlapping of multiple laser shocks. The increase of hardness is only for these processing conditions. The influence of the different overlapping ratio will be studied in the future.

Using standard $\sin ^{2} \Psi$ technique, the residual stresses of peened specimen were measured to be $56.6,25.2$ and $87.9 \mathrm{MPa}$ in compressive state for laser power density 3.4, 3.8 and 4.4 $\mathrm{GW} / \mathrm{cm}^{2}$ respectively. These results indicate laser induced shock introduces slightly residual compressive stress in the peened specimen. The effects of residual stress on indentation hardness tests have been extensively studied [13-15], among which, Chen et al. [15] show that a biaxial compressive stress in the surface leads to a smaller plastic zone underneath the indenter, to more pile-up and to increased hardness.

Fig. 5 shows XRD spectra of NiTi subjected to LSP with various laser power densities. For this study, the 2-theta scanning range $30^{\circ}<2 \theta<55^{\circ}$ was used, as the reflections corresponding to 


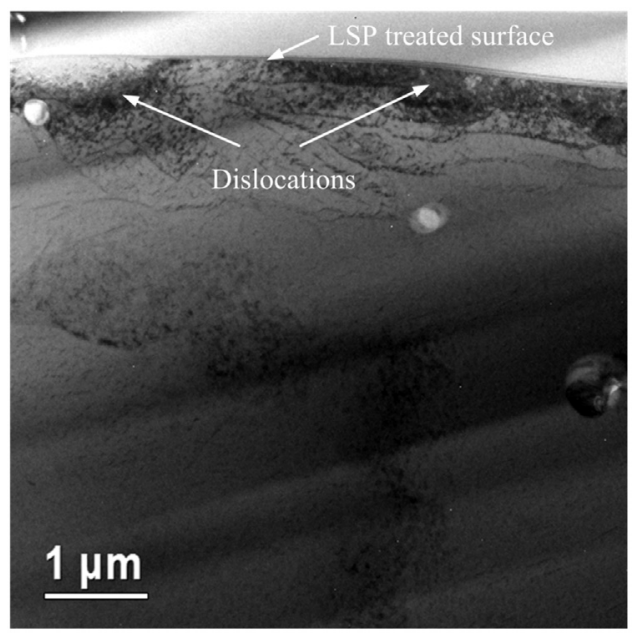

Fig. 6. Microstructure after LSP. Bright field TEM image showing dislocations at the surface.

crystallographic planes (002), (111) and (012) of B19' martensite phase and the plane (110) of B2 austenite phase were indexed in this range. As observed in Fig. 5, with increasing the laser power density from 0 to $4.4 \mathrm{GW} / \mathrm{cm}^{2}$, the intensity of austenite peak B2 (110) is gradually decreased, while there is no any sign of martensite peaks in the 2-theta scan range. These observations indicate that there is no phase transformation from austenite to martensite after LSP in our study. Liao et al. [10] observed the phase transformation of austenite into martensite when the laser power density is $4 \mathrm{GW} / \mathrm{cm}^{2}$ and the higher laser energy results in a higher volume fraction of martensite structures. But in their study, they used aluminum foil as absorption layer and BK-7 glass as confinement layer, which results in much higher shock pressure. It indicates there exists a threshold pressure for the austenitemartensite phase transformation in LSP process.

After LSP, dislocation was observed under the peened surface as in Fig. 6. The increase of dislocation density generated by LSP leads to an increase in hardness by work hardening mechanism [6]. Besides dislocations, amorphization was also observed under the peened surface as shown in Fig. 7. In the sample after LSP, halo rings can be observed in the diffraction pattern of surface layer. The appearance of halo rings can be ascribed to either very fine grains or amorphous phases. To clarify this, high resolution TEM work was carried out. Fig. 7b shows a representative HRTEM image taken from region $A$ of Fig. 7a. It can be observed that the microstructure is mainly amorphous except that the $\mathrm{Ni}_{4} \mathrm{Ti}_{3}$ phase remains crystalline, which can also be confined by the halo rings in the corresponding fast-Fourier-transform (FFT) pattern. Amorphization under the peened surface causes the intensity decrease of austenite peak B2 (110) in XRD measurements and could also contribute to the increase of surface hardness.

XRD and TEM observations show that laser-induced plastic deformation results in the amorphization of NiTi alloy. Plastic deformation of crystalline phase usually causes the accumulation of defects and the generation of chemical disorder which consequently results in the deformation induced crystal-to-amorphous transition. Amorphization of NiTi alloys during LSP process needs high impact pressure according to the plasticity theory. It is of particular interest to estimate the shock pressure in the LSP process. In the LSP process, the laser power density governs the peak pressure of laser induced shockwave which determines the plastic strain and strain rate of shock-induced deformation. The pressure induced by laser pulse reaches its peak within tens of nanoseconds, resulting in ultrahigh strain rate $\left(10^{5}-10^{7} \mathrm{~s}^{-1}\right)$ deformation of the material near the surface. The peak pressure induced
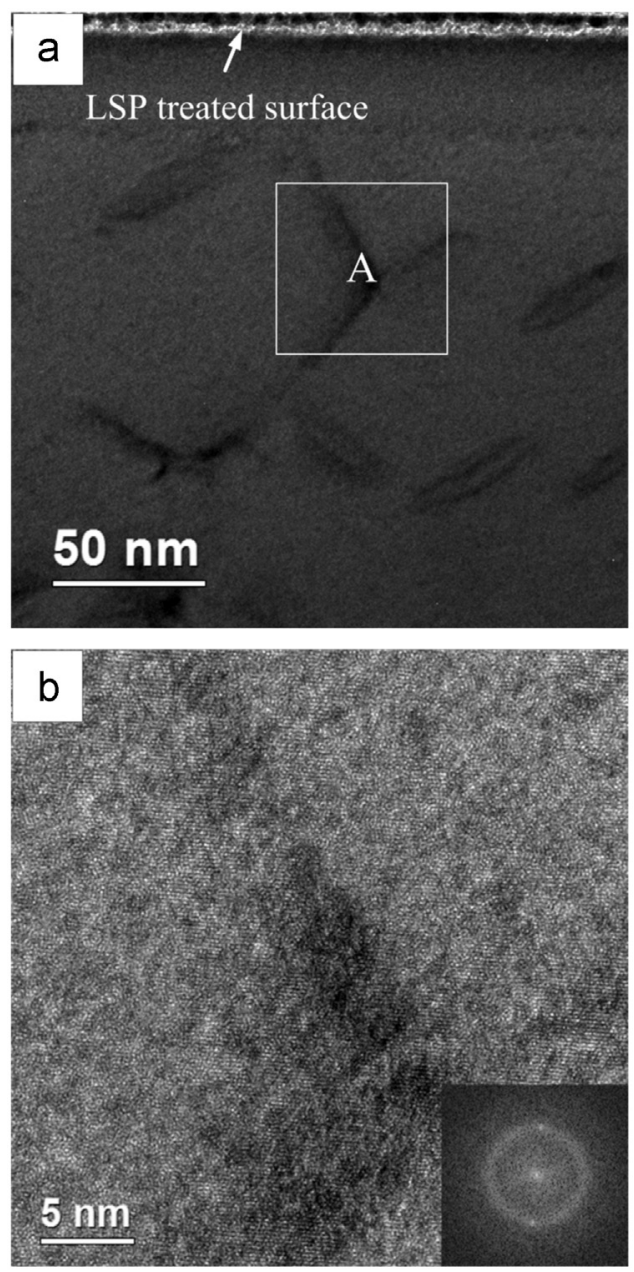

Fig. 7. Amorphization of NiTi surface after LSP. (a) Bright-field image showing amorphization but the $\mathrm{Ni}_{4} \mathrm{Ti}_{3}$ phase remaining crystalline. (b) high-resolution TEM images from region $\mathrm{A}$ and the corresponding FFT.

by laser pulse can be estimated by Fabbro's model [16],

$P(G P a)=0.01 \sqrt{\frac{\alpha}{2 \alpha+3}} \sqrt{Z\left(\mathrm{gcm}^{-2} \mathrm{~s}^{-1}\right)} \sqrt{I_{0}\left(G W \mathrm{~cm}^{-2}\right)}$

where $\alpha$ is the fraction of the internal energy devoted to the thermal energy (typically, $\alpha \approx 0.25$ ), $I_{0}$ is the laser power density and $Z=2 \quad Z_{1} Z_{2} /\left(Z_{1}+Z_{2}\right)$ is the reduced shock impedance between the absorption material (black paint, shock impedance $1.98 \times$ $10^{5} \mathrm{~g} \mathrm{~cm}^{-2} \mathrm{~s}^{-1}$ ) and the confining medium (water, shock impedance $1.45 \times 10^{5} \mathrm{~g} \mathrm{~cm}^{-2} \mathrm{~s}^{-1}$ ). The pressure transmitted into the $\mathrm{NiTi}$ material is enhanced due to the impedance mismatch between the absorption material and target material (NiTi, shock impedance $3.44 \times 10^{6} \mathrm{~g} \mathrm{~cm}^{-2} \mathrm{~s}^{-1}$ [17]). The peak pressure generated by the pulsed laser in this study varies from 3.9 to $4.5 \mathrm{GPa}$. The amorphous phase volume fraction can be simply estimated with the intensity of austenite peak B2 (110) shown in Fig. 5. The amorphous phase volume fraction is estimated to be $24 \%$ and $58 \%$ in the XRD probed region for the laser power density 3.4 and $4.4 \mathrm{GW} / \mathrm{cm}^{2}$ respectively. Assuming a linear dependence of amorphous phase volume fraction on the peak pressure, the threshold peak pressure for amorphization of NiTi alloy is about $3.3 \mathrm{GPa}$. The NiTi alloy with initial austenite phase could experience austenite-to-martensite transformation to accommodate the deformation under the shock loading as reported by Liao et al. [10]. They estimated the martensite volume fraction is about $22 \%$ for a SE508 NiTi alloy processed with $4 \mathrm{GW} / \mathrm{cm}^{2}$ in glass-confined LSP, which induces higher shock pressure than water-confined 


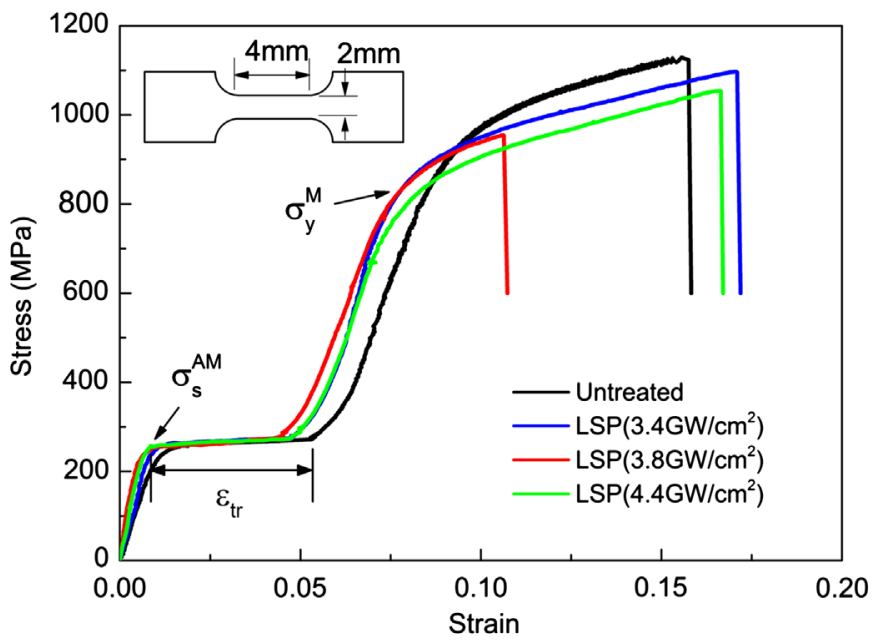

Fig. 8. Stress-strain curves of NiTi dog-bone specimen treated with various laser power densities.

Table 1

Characteristics of superelastic stress-strain curve of LSP treated NiTi specimen.

\begin{tabular}{llll}
\hline $\begin{array}{l}\text { Laser power density } \\
\left(\mathrm{GW} / \mathrm{cm}^{2}\right)\end{array}$ & $\begin{array}{l}\text { Transition } \\
\text { strain }(\%)\end{array}$ & $\begin{array}{l}\text { Transition stress } \\
(\mathrm{MPa})\end{array}$ & $\begin{array}{l}\text { Yield stress of } \\
\text { martensite }(\mathrm{MPa})\end{array}$ \\
\hline 0 & 4.90 & 256 & 963 \\
3.4 & 4.64 & 260 & 872 \\
3.8 & 4.37 & 253 & 821 \\
4.4 & 4.28 & 256 & 830 \\
\hline
\end{tabular}

mode used in our study. Based on our study and Liao et al.'s study [10], we speculate that their exist a transition from austeniteamorphous to austenite-martensite phase transformation if we increase the shock pressure in our LSP experiments.

Dog-bone specimens with the thickness of $0.4 \mathrm{~mm}$ were double-side peened and tested in uniaxial tension. Since the thickness of LSP affect layer is about $250-300 \mu \mathrm{m}$ as shown in Fig. 4, the double-side peened dog-bone specimen consists of the material fully processed by LSP. The measured stress-strain curves are shown in Fig. 8. Phase transformation from the austenite to martensite will occur when the stress reaches the transition stress, $\sigma_{s}^{A M}$. The maximum strain caused by the complete transformation is denoted by $\varepsilon_{t r}$. Continuous loading will result in the elastic deformation of the transformed martensite until the stress reaches the yield stress of the martensite $\sigma_{y}^{M}$. The effects of laser shock peening on those characteristics of superelasticity behavior are listed in Table 1 . The transition stress, $\sigma_{s}^{A M}$ shows almost no changes while the yield stress of martensite, $\sigma_{y}^{M}$, shows a decrease about $100 \mathrm{MPa}$ for the laser parameters studied. The peening shows effects on the maximum transition strain, $\varepsilon_{t r}$, however, showing a maximum reduction from $4.9 \%$ in untreated specimen to $4.3 \%$ in peened specimen treated with laser power density $4.4 \mathrm{GW} / \mathrm{cm}^{2}$ (a reduction of $0.6 \%$, about $12 \%$ loss compared to maximum transition strain of $4.9 \%$ ). There is no clear dependence of ductility on laser power density. This is probably because that the strain at fracture is very sensitive to the flaw introduced in specimen preparation. Ye et al. [18] used controlled annealing after the LSP process to introduce nanocrystallization in the surface which both preserves the ductility and enhances the strength of the material. Similar heat treatment method can be used here as well to produce bimodal microstructure which posses both high strength and high ductility.

\section{Conclusion}

In this study, microstructure and mechanical properties of austenite NiTi alloy treated with laser induced shock was investigated. It was found that the thickness of laser affected layer is about $250-300 \mu \mathrm{m}$. The hardness of the specimen is increased by approximately $10 \%$ after LSP. Laser induced shock introduces slightly residual compressive stress in the peened specimen. The ultrahigh-strain-rate plastic deformation by LSP results in dislocation substructure and amorphization underneath the surface which are responsible for the hardness increase. The superleastic stress-strain curves of the fully LSP processed material show no change in phase transition stress, about $100 \mathrm{MPa}$ decrease in martensite yield stress, and a loss of maximum transition strain about $12 \%$ after LSP. Since LSP is a surface processing technique, the shape memory behavior of the bulk material can be preserved. Thus, it is possible to prepare NiTi alloys with higher surface hardness and minimal loss of superelastic performance for biomedical and MEMS applications with LSP.

\section{Acknowledgments}

The authors would like to thank the National Natural Science Foundation of China (Grant nos. 11002150 and 10972228) and the Basic Research Equipment Project of Chinese Academy of Sciences (YZ200930) for financial support.

\section{References}

[1] K. Otsuka, C.M. Wayman, Shape Memory Materials, Cambridge University Press, Cambridge, 1999

[2] S. Shabalovskaya, J. Anderegg, J. Van Humbeeck, Acta biomater. 4 (2008) 447-467.

[3] J. Lindemann, C. Buque, F. Appel, Acta Mater. 54 (2006) 1155-1164.

[4] H.Y. Miao, D. Demers, S. Larose, C. Perron, M. Lévesque, J. Mater. Process. Technol. 210 (2010) 2089-2102.

[5] M. Klemenz, V. Schulze, I. Rohr, D. Löhe, J. Mater. Process. Technol. 209 (2009) 4093-4102.

[6] P. Peyre, R. Fabbro, Opt. Quantum Electron. 27 (1995) 1213-1229.

[7] C.S. Montross, T. Wei, L. Ye, G. Clark, Y.W. Mai, Int. J. Fatigue 24 (2002) 1021-1036.

[8] W. Zhang, Y.L. Yao, J. Manuf. Sci. Eng. 124 (2002) 369-378.

[9] Y. Wang, H. Chen, J.W. Kysar, Y. Lawrence Yao, J. Manuf. Sci. Eng. 129 (2007) $485-496$.

[10] Y. Liao, C. Ye, D. Lin, S. Suslov, G.J. Cheng, J. Appl. Phys. 112 (2012) 033515.

[11] S. Nemat-Nasser, J.-Y. Choi, W.-G. Guo, J.B. Isaacs, Mech. Mater. 37 (2005) 287-298.

[12] C. Eberl, D.S. Gianola, K.J. Hemker, Exp. Mech. 50 (2008) 85-97.

[13] S. Suresh, A.E. Giannakopoulos, Acta Mater. 46 (1998) 5755-5767.

[14] S. Carlsson, P.-L. Larsson, Acta Mater. 49 (2001) 2179-2191.

[15] X. Chen, J. Yan, A.M. Karlsson, Mater. Sci. Eng.: A 416 (2006) 139-149.

[16] L. Berthe, R. Fabbro, P. Peyre, L. Tollier, E. Bartnicki, J. Appl. Phys. 82 (1997) 2826.

[17] J.C.F. Millett, N.K. Bourne, G.T. Gray, J. Appl. Phys. 92 (2002) 3107-3110.

[18] C. Ye, S. Suslov, X. Fei, G.J. Cheng, Acta Mater. 59 (2011) 7219-7227. 